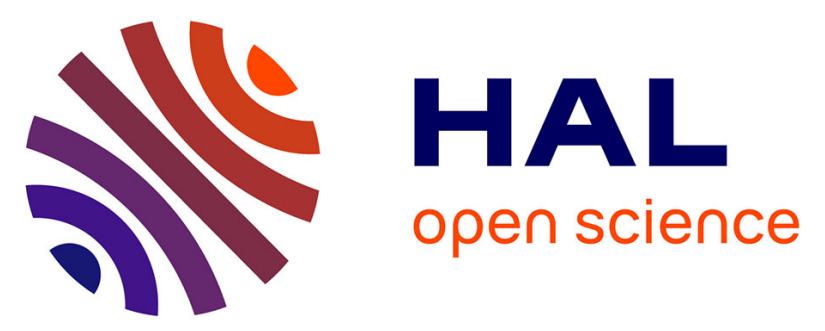

\title{
Comparison of idiopathic (isolated) aortitis and giant cell arteritis-related aortitis. A French retrospective multicenter study of 117 patients
}

Olivier Espitia, Maxime Samson, Thomas Le Gallou, Jérôme Connault, Cédric Landron, Christian Lavigne, Cristina Belizna, Julie Magnant, Claire de Moreuil, Pascal Roblot, et al.

\section{To cite this version:}

Olivier Espitia, Maxime Samson, Thomas Le Gallou, Jérôme Connault, Cédric Landron, et al.. Comparison of idiopathic (isolated) aortitis and giant cell arteritis-related aortitis. A French retrospective multicenter study of 117 patients. Autoimmunity Reviews, 2016, 15 (6), pp.571-576. 10.1016/j.autrev.2016.02.016 . hal-01278610

HAL Id: hal-01278610 https://hal-univ-rennes1.archives-ouvertes.fr/hal-01278610

Submitted on 3 Oct 2016

HAL is a multi-disciplinary open access archive for the deposit and dissemination of scientific research documents, whether they are published or not. The documents may come from teaching and research institutions in France or abroad, or from public or private research centers.
L'archive ouverte pluridisciplinaire HAL, est destinée au dépôt et à la diffusion de documents scientifiques de niveau recherche, publiés ou non, émanant des établissements d'enseignement et de recherche français ou étrangers, des laboratoires publics ou privés. 


\section{Accepted Manuscript}

Comparison of idiopathic (isolated) aortitis and giant cell arteritis-related aortitis. A French retrospective multicenter study of 117 patients

Olivier Espitia, Maxime Samson, Thomas Le Gallou, Jérôme Connault, Cedric Landron, Christian Lavigne, Cristina Belizna, Julie Magnant, Claire de Moreuil, Pascal Roblot, François Maillot, Elisabeth Diot, Patrick Jégo, Cécile Durant, A. Masseau, Jean-Marie Brisseau, Pierre Pottier, Alexandra Espitia-

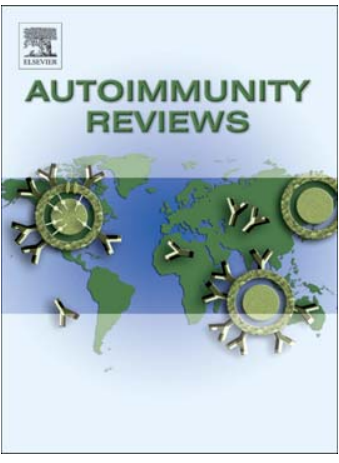
Thibault, Anabele Dos Santos, François Perrin, Mathieu Artifoni, Antoine Néel, Julie Graveleau, Philippe Moreau, Hervé Maisonneuve, Georges Fau, Jean-Michel Serfaty, Mohamed Hamidou, Christian Agard

$\begin{array}{ll}\text { PII: } & \text { S1568-9972(16)30043-X } \\ \text { DOI: } & \text { doi: 10.1016/j.autrev.2016.02.016 } \\ \text { Reference: } & \text { AUTREV } 1834\end{array}$

To appear in: $\quad$ Autoimmunity Reviews

Received date: 9 February 2016

Accepted date: 14 February 2016

Please cite this article as: Espitia Olivier, Samson Maxime, Le Gallou Thomas, Connault Jérôme, Landron Cedric, Lavigne Christian, Belizna Cristina, Magnant Julie, de Moreuil Claire, Roblot Pascal, Maillot François, Diot Elisabeth, Jégo Patrick, Durant Cécile, Masseau A, Brisseau Jean-Marie, Pottier Pierre, Espitia-Thibault Alexandra, Santos Anabele Dos, Perrin François, Artifoni Mathieu, Néel Antoine, Graveleau Julie, Moreau Philippe, Maisonneuve Hervé, Fau Georges, Serfaty Jean-Michel, Hamidou Mohamed, Agard Christian, Comparison of idiopathic (isolated) aortitis and giant cell arteritisrelated aortitis. A French retrospective multicenter study of 117 patients, Autoimmunity Reviews (2016), doi: 10.1016/j.autrev.2016.02.016

This is a PDF file of an unedited manuscript that has been accepted for publication. As a service to our customers we are providing this early version of the manuscript. The manuscript will undergo copyediting, typesetting, and review of the resulting proof before it is published in its final form. Please note that during the production process errors may be discovered which could affect the content, and all legal disclaimers that apply to the journal pertain. 
Comparison of idiopathic (isolated) aortitis and giant cell arteritis-related aortitis. A French retrospective multicenter study of 117 patients.

Olivier Espitia ${ }^{1}$, Maxime Samson ${ }^{2}$, Thomas Le Gallou ${ }^{3}$, Jérôme Connault ${ }^{1}$, Cedric Landron ${ }^{4}$, Christian Lavigne ${ }^{5}$, Cristina Belizna ${ }^{5}$, Julie Magnant ${ }^{6}$, Claire de Moreuil ${ }^{7}$, Pascal Roblot ${ }^{4}$, François Maillot ${ }^{6}$, Elisabeth Diot ${ }^{6}$, Patrick Jégo ${ }^{3}$, Cécile Durant ${ }^{1}$, A. Masseau ${ }^{1}$, Jean-Marie Brisseau $^{1}$, Pierre Pottier ${ }^{1}$, Alexandra Espitia-Thibault ${ }^{1}$, Anabele Dos Santos ${ }^{8}$, François Perrin $^{1}$, Mathieu Artifoni ${ }^{1}$, Antoine $\mathrm{Née}^{1}$, Julie Graveleau ${ }^{9}$, Philippe Moreau ${ }^{10}$, Hervé Maisonneuve ${ }^{11}$, Georges $\mathrm{Fau}^{12}$, Jean-Michel Serfaty ${ }^{12}$, Mohamed Hamidou ${ }^{1}$, Christian Agard ${ }^{1}$.

${ }^{1}$ Department of Internal Medicine, University Hospital of Nantes, France

${ }^{2}$ Department of Internal Medicine and Clinical Immunology, University Hospital of Dijon,

France

${ }^{3}$ Department of Internal Medicine, University Hospital of Rennes, France

${ }^{4}$ Department of Internal Medicine, University Hospital of Poitiers, France

${ }^{5}$ Department of Internal Medicine, University Hospital of Angers, France

${ }^{6} \mathrm{CHRU}$ of Tours, department of Internal Medicine, France

${ }^{7}$ Department of Internal Medicine, University Hospital of Brest, France

${ }^{8}$ Department of Hematology, Hospital of Vannes, France

${ }^{9}$ Department of Medicine, Hospital of Saint-Nazaire, France

${ }^{10}$ Department of Hematology, Hospital of Lorient, France

${ }^{11}$ Department of Hematology, Hospital of La Roche sur Yon, France

${ }^{12}$ Department of Radiology, University Hospital of Nantes, France

\section{Corresponding Author:}

Pr Christian Agard

Department of Internal Medicine,

Hôtel-Dieu, Centre Hospitalier Universitaire de Nantes

1 place Alexis Ricordeau 44093 Nantes, France.

Tel: +33240084933 Fax: +33240083 379

E-mail : christian.agard@chu-nantes.fr 


\section{Abstract}

Objectives: The aim of the study was to compare clinical/imaging findings and outcome in patients with idiopathic (isolated aortitis, IA) and with giant cell arteritis (GCA)-related aortitis.

Methods: Patients from 11 French internal medicine departments were retrospectively included. Aortitis was defined by aortic wall thickening $>2 \mathrm{~mm}$ and/or an aortic aneurysm on CT-scan, associated to inflammatory syndrome. Patients with GCA had at least 3 ACR criteria. Aortic events (aneurysm, dissection, aortic surgeries) were reported, and free of aortic events-survival were compared.

Results: Among 191 patients with non-infectious aortitis, 73 with GCA and 44 with IA were included. Patients with IA were younger (65 vs $70 \mathrm{y}, \mathrm{p}=0.003$ ) and comprised more past/current smokers (43 vs $15 \%, \mathrm{p}=0.0007$ ). Aortic aneurisms were more frequent (38\% vs 20\%, $\mathrm{p}=0.03$ ) and aortic wall thickening was more pronounced in IA. During follow-up (median=34 months), subsequent development of aortic aneurysm was significantly lower in GCA when compared to IA ( $\mathrm{p}=0.009$ ). GCA patients required significantly less aortic surgery during follow-up than IA patients $(\mathrm{p}=0.02)$. Mean age, sex-ratio, inflammatory parameters and free of aortic aneurism-survival were equivalent in patients with $\mathrm{IA} \geq 60 \mathrm{y}$ when compared to patients with GCA-related aortitis.

Conclusions: IA is more severe than aortitis related to GCA, with higher proportions of aortic aneurism at diagnosis and during follow-up. IA is a heterogeneous disease and its prognosis is worse in younger patients $<60 \mathrm{y}$. Most patients with $\mathrm{IA} \geq 60 \mathrm{y}$ share many features with GCArelated aortitis.

Keywords: Aortitis, giant cell arteritis, idiopathic aortitis, isolated aortitis, aortic aneurysm 


\section{Introduction}

Aortitis is a general term for a spectrum of disorders characterized by inflammation of the aortic wall [1]. The main underlying diseases causing non-infectious aortitis are giant cell arteritis (GCA) and Takayasu arteritis [2,3] and more rarely, sarcoidosis, Behçet's disease, Cogan syndrom, granulomatosis with polyangiitis, spondylarthropathy, IgG4-related disease, or relapsing polychondritis. In addition, idiopathic (isolated) aortitis (IA) has also been described [4]. Aortitis is related to significant morbidity and mortality through the development of aortic aneurysm, aortic wall rupture, aortic acute dissection, and/or thrombotic luminal obstruction [5]. Surgical series have found that granulomatous/giant cell aortitis is the most common histological pattern of aortitis [2]. However, many patients do not require surgery and aortitis is usually diagnosed when a significant aortic thickening (generally $>2 \mathrm{~mm}$ ) is found on computed tomography (CT) or magnetic resonance imaging (MRI).

GCA is the most frequent vasculitis in patients above $60 \mathrm{y}$, typically affecting temporal arteries, but involving also large arteries like proximal limb arteries [6] or the aorta. The estimated prevalence of aortitis in GCA ranges from 33 to 65\% [7-9], and aortic aneurysm or ectasia have been found in about $10-15 \%$ of patients at the time of diagnosis of GCA [7, 8, 10-14]. Regarding IA, most of studies have included surgical cases, especially of the ascending aorta, and IA accounts for 4-8\% of surgical aortitis cases [15]. In practice, many patients with IA above 50 or $60 \mathrm{y}$ are considered as having GCA-related aortitis, even if they do not fulfill the "American College of Rheumatology" (ACR) diagnosis criteria. However, it is not clear if IA above 50-60y represent variants of GCA [16]. In fact, differences between IA and GCA-related aortitis have never been clearly studied in a non-surgical population. Data are also lacking about epidemiology, optimal treatment, monitoring and prognosis of patients with IA or with GCA-related aortitis. Thus, the aim of the present study was to 
describe the initial clinical and CT-scan aortic characteristics, the treatment used and to analyze the outcome of patients with IA or GCA-related aortitis, in order to underline potential common features or differences between these 2 entities.

\section{Methods}

This retrospective multicenter study was conducted in French internal medicine departments of 7 university hospitals and 4 non-university hospitals. All patients with a diagnosis of non-infectious aortitis assessed between January 2000 and December 2014 were identified. Aortitis was defined by an aortic wall thickening $>2 \mathrm{~mm}$ on CT-scan [17] and/or an aortic aneurysm, associated to inflammatory syndrome (CRP $>5 \mathrm{mg} / \mathrm{L}$ and/or fibrinogen $>4 \mathrm{~g} / \mathrm{L}$ ) unexplained by any other cause. Finally, only patients with GCA-related aortitis or IA were included. At least 3 ACR criteria, including age over 50, were required for GCA diagnosis [18]. IA was defined by aortitis, associated to inflammatory syndrome, without any other ACR criteria for GCA excepted the age [18], and without any diagnosis criteria for or any other causes of aortitis $[19,20]$.

Flow chart is summarized in figure 1. Two physicians (OE, CA) analyzed each medical file, aiming to classify patients with either GCA-related aortitis or IA. Initial clinical data, biological parameters, aortic CT-scan findings and treatment modalities were analyzed. Follow-up data, therapeutics, evolution of aortic imaging, and aortic events were also studied at the time of the last visit. An aortic event was defined by the subsequent occurrence of an aortic aneurysm, ectasia, dissection or stenosis, on CT-scan or on Doppler ultrasonography, only in patients free of any of these features at the time of diagnosis. This study was approved by the local ethics review committee.

For statistical analyses, results were expressed by mean \pm standard deviation (SD) or as median, range. Categorical variable were compared using Chi-square tests or Fisher's exact 
tests when any of the expected cell counts of a $2 \times 2$ table was less than 5. Comparisons of quantitative variables were performed using Student's $t$-test. A $p$-value $<0.05$ was considered to be statistically significant. Survival curves were made to compare GCA-related aortitis and IA patients. Aortic event free-survival were compared between groups. Thus, the aortic events at the time of aortitis diagnosis were excluded from analysis, and only new subsequent events were considered. To analyze the free of aortic aneurism survival, patients with aortic aneurism at diagnosis were excluded. Progression of aortic aneurysm was not considered as an aortic event. To analyze the free of aortic surgery survival, patients with aortic surgery at diagnosis were excluded. To analyze the free of aortic dissection survival, patients with aortic dissection at diagnosis were excluded. Kaplan-Meier curves were then made and a log-rank test was performed to compare aortic event-free survivals. Stastistical analyses were all performed with Graph Pad Prism v5 software.

\section{Results}

This study analyzed 117 cases of aortitis: 73 GCA-related aortitis, 44 IA including 29 $\geq 60 \mathrm{y}$ and $15<60 \mathrm{y}$. Eighty-five patients were women, mean age at aortitis diagnosis was $67.5 \mathrm{y}$ [range:37-87]. In the GCA-related aortitis group, headache was present in $65.8 \%$ of the patients, weight loss in $53.4 \%$, fever in $42.5 \%$, polymyalgia rheumatica (PMR) in $26 \%$, hyperesthesia of the scalp in $13.7 \%$, jaw claudication in $12.3 \%$, and ocular involvement in 9.6\%. Every patient from the GCA-related aortitis group had undergone a temporal artery biopsy (TAB) with GCA consistent lesions in 51 cases. Among the 22 cases with negative TAB, $81.8 \%$ had headache, 31.8\% had PMR, 27.3\% had hyperesthesia of the scalp and $13.6 \%$ had jaw claudication. Among IA cases, 34.1\% had weight loss, 34.1\% fever and none had ocular involvement. TAB was performed in $70.5 \%$ of IA patients and was negative. 
Symptoms leading to the diagnosis of aortitis were thoracic or abdominal pain in $26 \%$ of the patients, dyspnea in $23 \%$, cough in $17 \%$. Thoracic or abdominal pain tended to be more frequent in patients with IA $(34.1 \%$ vs $17.8 \%, \mathrm{p}=0.07)$. Conversely, cough was more frequent among GCA-related aortitis $(24.7 \%$ vs $9.1 \%$ in IA, $\mathrm{p}=0,05)$. In almost half of cases, aortitis was found in patients with isolated inflammatory syndrome. A majority of our GCA patients $(n=52)$ had undergone a systematic CT-scan at the time of GCA diagnosis, and aortitis was found at that time in 50 patients. In 23 cases, aortitis was diagnosed after GCA and mean time between GCA and aortitis diagnosis was 49 months [range: 2-143] for these patients.

Main characteristics of patients with GCA-related aortitis and IA are presented in table 1. Mean age in GCA-related aortitis patients was significantly higher. Past/current smokers were significantly more found among IA patients. Location of aortic involvement was not significantly different. However, aortic aneurysm were significantly more found in patients with IA (38.6\% vs. $20.5 \%, \mathrm{p}=0.03)$ and mean maximal thickening of the aortic wall was higher in the IA group.

Corticosteroids was given to all the 73 patients with GCA-related aortitis and to 40 patients with IA (91\%). Indeed, four patients with IA did not receive any specific treatment because of well tolerated inflammation. Among IA patients, treatment was deliberately delayed in 7 cases because of non symptomatic inflammation. Prednisone was the sole oral steroid therapy used, started at the mean daily dose of $0.8 \pm 0.2 \mathrm{mg} / \mathrm{kg}$ in GCA-related aortitis and $0.82 \pm 0.2 \mathrm{mg} / \mathrm{kg}$ in IA. At aortitis diagnosis, 52 GCA-related aortitis patients $(71.2 \%)$ and 27 IA patients $(61.4 \%)$ were treated with oral platelet aggregation inhibitors, and respectively $17(23.3 \%)$ and $15(34.1 \%)$ had statins, 31 (42.5\%) and 19 IA (43.2\%) had high blood pressure medication, $15(20.5 \%)$ and $13(29.5 \%)$ had beta-blockers, which was equally distributed in both groups. 
Median follow-up was 34 months in GCA-related aortitis and 34.5 months in IA $(p=0,90)$. The majority of our aortitis patients $(n=90 / 117,77 \%)$ were only treated with steroids while 17 in the GCA-related aortitis group (23\%) and 10 in the IA group (22.7\%) required alternate therapy: methotrexate (13 GCA, 7 IA), azathioprine (7 GCA, 3 IA), IV cyclophosphamide (5 GCA, 4 IA), tocilizumab (1 GCA, 2 IA), and anakinra 1 IA).

\begin{tabular}{|c|c|c|c|}
\hline & $\begin{array}{l}\text { GCA-Ao } \\
n=73\end{array}$ & $\begin{array}{l}\text { IA } \\
n=44\end{array}$ & $p$-value \\
\hline Age (median, years) [min-max] & $70[52-83]$ & $65.0[37-87]$ & 0.0003 \\
\hline Female, $\mathrm{n}(\%)$ & $57(78.1)$ & $28(63.6)$ & 0.09 \\
\hline Biological parameters $\pm \mathrm{SD}$ & $\longrightarrow$ & & \\
\hline Mean CRP (mg/L) & $111.3 \pm 78.3$ & $109.9 \pm 79.6$ & 0.93 \\
\hline $\mathrm{ESR}, \mathrm{mm} / \mathrm{h}$ & $70.5 \pm 38.1$ & $53.2 \pm 49.2$ & 0.18 \\
\hline Fibrinogen $(\mathrm{g} / \mathrm{L})$ & $7.5 \pm 1.8$ & $6.9 \pm 2.4$ & 0.30 \\
\hline Albumin $(\mathrm{g} / \mathrm{L})$ & $31.1 \pm 6.2$ & $33.2 \pm 6.0$ & 0.42 \\
\hline Hémoglobin (g/dL) & $10.9 \pm 1.5$ & $11.2 \pm 2.0$ & 0.38 \\
\hline Plaquettes (G/L) & $429.4 \pm 132.8$ & $380.6 \pm 171.4$ & 0.10 \\
\hline \multicolumn{4}{|l|}{ Cardiovascular risk factors, $\mathrm{n}(\%)$} \\
\hline Obesity $\left(\mathrm{BMI} \geq 30 \mathrm{~kg} / \mathrm{m}^{2}\right)$ & $8(11.0)$ & $5(11.4)$ & 1.00 \\
\hline Arterial hypertension & $30(41.1)$ & $20(45.5)$ & 0.64 \\
\hline Diabetes mellitus & $5(6.8)$ & $2(4.5)$ & 0.71 \\
\hline Hypercholesterolemia & $18(24.7)$ & $7(15.9)$ & 0.26 \\
\hline Ever smoker & $11(15.1)$ & $19(43.2)$ & 0.0007 \\
\hline \multicolumn{4}{|l|}{ Location of aortic involvement, $\mathrm{n}(\%)$} \\
\hline Ascending aorta & $48(65.8)$ & $29(65.9)$ & 1.00 \\
\hline Arch & $55(75.3)$ & $32(72.7)$ & 0.75 \\
\hline Descending aorta & $6(84.9)$ & $32(72.7)$ & 0.15 \\
\hline Suprarenal abdominal aorta & $46(63.0)$ & $20(45.5)$ & 0.06 \\
\hline Subrenal abdominal aorta 1 & $45(61.6)$ & $20(45.5)$ & 0.09 \\
\hline Entire aorta & $29(39.7)$ & $11(25.0)$ & 0.10 \\
\hline \multicolumn{4}{|l|}{ Type of aortic involvement as, $\mathrm{n}(\%)$} \\
\hline Aneurysm, & $15(20.5)$ & $17(38.6)$ & 0.03 \\
\hline Ascending thoracic aneurysm & $14(19.2)$ & $13(39.5)$ & 0.20 \\
\hline Abdominal aneurysm & $1(1.4)$ & $3(6.8)$ & 0.14 \\
\hline Ectasia & $5(6.8)$ & $1(2.3)$ & 0.41 \\
\hline Wall thickening & $70(95.9)$ & $41(93.2)$ & 0.67 \\
\hline Dissection & $5(6.8)$ & $3(6.8)$ & 1.00 \\
\hline Aortic maximal thickening, mm, mean \pm SD & $3.9 \pm 1.5$ & $4.57 \pm 1.5$ & 0.08 \\
\hline Aortic stenosis, & $0(0.0)$ & $0(0.0)$ & 1.00 \\
\hline Aortic thrombosis & $2(2.7)$ & $1(2.3)$ & 1.00 \\
\hline
\end{tabular}


Table 1: Comparison of demographics, biologic parameters, cardiovascular risk factors and aortic findings on CT-scan between patients with GCA-related aortitis (GCA-Ao) and patients with IA, at the time of aortitis diagnosis.

Aortic CT-scan was performed during follow-up in 63\% of GCA-related aortitis patients and in $68.2 \%$ of IA patients. The entire aortic complications identified in both groups are presented in table 2. Twenty-four IA patients (54.5\%) underwent at least one aortic event as compared to 20 GCA-related aortitis patients $(27.4 \%, \mathrm{p}=0.003)$. Respectively, 4 patients with GCA-related aortitis and 6 patients with IA developed new aortic aneurysm during follow-up. Thus, a total of 41 patients (35\%) had aortic aneurismal disease, which was significantly more frequent among IA patients (50\% vs $26 \%, \mathrm{p}=0.008)$. In 2 cases, aortic aneurysm occurred in IA patients who had not been specifically treated for aortitis.

\begin{tabular}{|l|l|l|l|}
\hline & $\begin{array}{l}\text { GCA-Ao } \\
\mathbf{n = 7 3}\end{array}$ & $\begin{array}{l}\text { IA } \\
\mathbf{n = 4 4}\end{array}$ & $\boldsymbol{p}$-value \\
\hline Aortic aneurysm, n (\%) & $19(26.0)$ & $22(50.0)$ & $\mathbf{0 . 0 0 8}$ \\
\hline Aortic ectasia, n (\%) & $3(4.1)$ & $2(4.5)$ & 1.00 \\
\hline Aortic dissection, $\mathrm{n}(\%)$ & $6(8.2)$ & $6(13.1)$ & 0.36 \\
\hline Aortic stenosis, n (\%) & $0(0)$ & $1(2.3)$ & 0.37 \\
\hline Aortic surgery, n (\%) & $10(13.7)$ & $16(36.4)$ & $\mathbf{0 . 0 0 4}$ \\
\hline
\end{tabular}

Table 2: Aortic events identified at diagnosis and during follow-up (median follow-up=34 months) among 117 patients with aortitis, including 73 patients with GCA-related aortitis and 44 with idiopathic aortitis (IA).

Aortic surgery during follow-up was required in 4 patients with GCA (5.4\%) and in 8 patients with IA (18\%). Overall, aortic surgery (at diagnosis and during follow-up) was more frequently performed in the IA group than in the GCA-related aortitis group (36.4\% vs $13.7 \%$, 
$\mathrm{p}=0.004)$. Bentall procedure was performed in 17 cases (7 GCA, 11 IA), aortic endoprosthesis in 5 cases ( 3 GCA, 2 IA) and aortic repair in 3 IA patients. In 23 cases, (8 GCA, 15 IA), aortic pathological examination was available and giant cells in the aortic wall were noted in 17 patients (5 GCA, 12 IA).

At the end of the follow-up, 10 patients had died, 6 in the GCA group (8.2\%), and 4 in the IA group $(9.1 \%, \mathrm{NS})$. Median time between aortitis diagnosis and death was 26 months for GCArelated aortitis and 30 months for IA. Five patients ( 2 with GCA, 3 with IA) had relapsing inflammatory disease and uncontrolled aortitis. One IA patient died because of aortic aneurysm rupture.

As IA may represent a heterogeneous entity, we compared IA patients according to the age $<$ or $\geq 60 \mathrm{y}$. The proportion of women was higher among IA patients $\geq 60 \mathrm{y}(69 \% \mathrm{vs}$. 53.3\%). Inflammatory parameters and cardiovascular risk factors except smoking were not different. Past/current smokers were predominantly found in patients with IA under 60y (66.7\% vs. $31 \%, \mathrm{p}=0.02)$. Aneurism, ectasia, wall thickening, and aortic dissection were similar in both groups. IA patients $\geq 60 \mathrm{y}$ had more descending aorta involvement $(82.4 \%)$ than IA patients $<60 \mathrm{y}(53.3 \%, \mathrm{p}=0.04)$.

As IA $\geq 60 y$ may overlap with GCA-related aortitis, we then compared these both groups (table 3). Median age, sex ratio and biological inflammatory parameters were remarkably close. Cardiovascular risk factors were equally distributed. Proportions of patients with involvement of ascending aorta, descending aorta, and the entire aorta were also very close in both groups. 


\begin{tabular}{|c|c|c|c|}
\hline & $\begin{array}{l}\text { GCA } \\
n=73\end{array}$ & $\begin{array}{l}\text { IA } \geq 60 y \\
n=29\end{array}$ & $p$-value \\
\hline Median age (years) (min-max) & $70(52-83)$ & $69.8(60-87)$ & 0.90 \\
\hline Female, $\mathrm{n}(\%)$ & $57(78.1)$ & $20(69.0)$ & 0.19 \\
\hline \multicolumn{4}{|l|}{ Biological parameters $\pm \mathrm{SD}$} \\
\hline Mean CRP mg/L & $111.3 \pm 78.3$ & $117.5 \pm 76.3$ & 0.74 \\
\hline $\mathrm{ESR}, \mathrm{mm} / \mathrm{h}$ & $70.5 \pm 38.1$ & $65.6 \pm 30.9$ & 0.71 \\
\hline Fibrinogen $\mathrm{g} / \mathrm{L}$ & $7.5 \pm 1.8$ & $6.9 \pm 2.4$ & 0.38 \\
\hline Albumin $\mathrm{g} / \mathrm{L}$ & $31.1 \pm 6.2$ & $34.2 \pm 6.2$ & 0.18 \\
\hline Hémoglobin $\mathrm{g} / \mathrm{dL}$ & $10.9 \pm 1.5$ & $11.2 \pm 1.9$ & 0.41 \\
\hline Plaquettes G/L & $429.4 \pm 132.8$ & $380.2 \pm 192.1$ & 0.21 \\
\hline \multicolumn{4}{|l|}{ Cardiovascular risk factors, $\mathrm{n}(\%)$} \\
\hline Obesity $\left(\mathrm{BMI} \geq 30 \mathrm{~kg} / \mathrm{m}^{2}\right)$ & $8(11.0)$ & $2(6.9)$ & 0.53 \\
\hline Arterial hypertension & $30(41.1)$ & $14(48.3)$ & 0.78 \\
\hline Diabetes mellitus & $5(6.8)$ & $1(3.4)$ & 0.67 \\
\hline Hypercholesterolemia & $18(24.7)$ & $6(20.7)$ & 0.67 \\
\hline Ever smoker & $11(15.1)$ & $9(31.0)$ & 0.07 \\
\hline \multicolumn{4}{|l|}{ Location of aortic involvement, $\mathrm{n}(\%)$} \\
\hline Ascending aorta & $48(65.8)$ & $19(65.5)$ & 0.33 \\
\hline Arch & $55(75.3)$ & $21(72.4)$ & 0.76 \\
\hline Descending aorta & $62(84.9)$ & $24(82.4)$ & 0.77 \\
\hline Abdominal aorta, suprarenal & $46(63.0)$ & $14(48.3)$ & 0.17 \\
\hline Abdominal aorta, subrenal & 45 (61.6) & $11(37.9)$ & 0.03 \\
\hline Entire aorta & $29(39.7)$ & $7(24.1)$ & 0.14 \\
\hline \multicolumn{4}{|l|}{ Type of aortic involvement, $\mathrm{n}(\%)$} \\
\hline Aneurysm & $15(20.5)$ & $14(48.3)$ & 0.005 \\
\hline Ectasia & $5(6.8)$ & $1(3.4)$ & 0.51 \\
\hline Wall thickening & $70(95.9)$ & $26(89.7)$ & 0.34 \\
\hline Dissection & $5(6.8)$ & $2(6.9)$ & 1.00 \\
\hline Mean of maximum thickening, $\mathrm{mm}( \pm \mathrm{SD})$ & $3.9( \pm 1.5)$ & $4.7( \pm 1.8)$ & 0.03 \\
\hline Aortic stenosis & $0(0.0)$ & $0(0.0)$ & 1.00 \\
\hline Aortic thrombosis & $2(2.7)$ & $0(0.0)$ & 1.00 \\
\hline
\end{tabular}

Table 3: Comparison of demographics, biologic parameters, cardiovascular risk factors and aortic findings on CT-scan between patients with aortitis related to GCA (GCA-Ao) and patients with $I A \geq 60 \mathrm{y}$, at the time of aortitis diagnosis.

Further, we analyzed the free of aortic events long-term survival (figure 2). Among 85 patients (58 GCA, 27 IA) without aortic aneurism at aortitis diagnosis, subsequent development of aortic aneurysm was significantly lower in GCA when compared to IA $(\mathrm{p}=0.009)$ (figure 2A). Analysis of 101 patients free of aortic surgery at aortitis diagnosis (65 
GCA, 36 IA), showed that GCA patients required significantly less aortic surgery during follow-up than IA patients ( $\mathrm{p}=0.02$ ) (figure 2B). Among 109 patients (68 GCA, 41 IA) without aortic dissection at aortitis diagnosis, subsequent occurrence of aortic dissection was lower in GCA (figure 2C). Finally, the free of aortic aneurism survival was equivalent among GCA-related aortitis patients and $I A \geq 60 \mathrm{y}$ patients (figure 1D). Moreover, this survival was significantly worse among IA patients $<60 \mathrm{y}(\mathrm{p}=0.003)$.

\section{Discussion}

Both IA and GCA-related aortitis are rare diseases for which epidemiological or therapeutic data are lacking. In the revised nomenclature of vasculitis, IA is considered separately [21], but the hypothesis that some IA patients over 50 or $60 \mathrm{y}$ do have GCA is often discussed in practice. Our study is the first to investigate clinical and imaging findings, outcome and prognosis of GCA-related aortitis and IA in a large French population. Our aortitis cases distinguish from previous surgical series describing aortic histological findings $[3,15,22,23]$.

Our study describes how GCA-related aortitis and IA were diagnosed. Weight loss, fever, inflammatory state were found in both conditions. Cough was more frequent among patients with GCA, which is not surprising, as it is a frequent manifestation of GCA [24]. The main finding was that clinical signs of aortic aneurismal disease like dyspnea, thoracic or abdominal pain were more frequent in IA. This is consistent with the fact that aortic aneurism were more frequent. Surprisingly, we found more smokers among IA patients and smoking could contribute to generate more severe aortic damages. In fact, we hypothesize that aortitis among GCA patients was found at an earlier stage, with less aneurism and lower aortic wall thickening. This can be explained by the systematic screening of aortic involvement in 
numerous patients with GCA $[8,12]$. Such systematic screening is controversial but recently, the French research group on GCA recommended an aortic CT-scan for each patient at the time of diagnosis of GCA [25].

In GCA, the management of aortic involvement (initial dose regimen, duration, monitoring) remains to be determined [26-28]. The benefit of steroid therapy to prevent subsequent development of aortic aneurismal disease remains elusive in patients with aortic inflammatory thickening. To treat large large-vessel vasculitis, the EULAR (european league against rheumatism) recommends corticosteroid at $1 \mathrm{mg} / \mathrm{kg} / \mathrm{day}$ of prednisone during 1 month, followed by a gradual decline [25, 29], associated with antiplatelet treatment and management of cardiovascular risk factors [7]. Moreover, blood pressure should be controlled, and the use of beta-blocker is recommended to reduce the growth of aneurysms. Antiplatelet therapy was given to 79 of the entire cohort $(67.5 \%)$. The benefit of this therapy in patients with aortitis is not really demonstrated and a recent cumulative meta-analysis showed that antiplatelet/anticoagulant therapy prior to the diagnosis of GCA was not associated with reduction in severe ischemic complications [30]. However, such a therapy may prevent from severe ischemic events after the diagnosis of GCA [30].

Despite the absence of any subsequent systematic scheduled aortic monitoring, our study have described the occurrence of new aortic aneurism, in 4/73 cases of GCA and in 6/44 cases of IA. The incidence of new aortic aneurism is probably higher. As 2 of 4 untreated IA patients developed new aneurism, therapeutic abstention should be avoided. However, treatment with prednisone 0.7 or $1 \mathrm{mg} / \mathrm{kg} / \mathrm{day}$ might be not sufficient to prevent aortic aneurysm occurrence.

Aortic involvement in GCA is potentially serious and the incidence of aortic aneurysm/dissection has been found to be increased 5 years after GCA diagnosis [31, 32]. Moreover, the survival of GCA patients with aortic aneurysm or dissection has been found to 
be decreased regarding standardized mortality ratio at 2.63 [31]. The prognosis of GCA patients with aortitis is unknown, but inflammatory thickening of the aortic wall may completely regress after 3-6 months steroids therapy $[7,13]$ and in some patients, aortitis might be totally cured. We previously found that these patients might have more GCA relapses, and higher cardiovascular mortality [14] but this remains to be prospectively demonstrated. Currently, predictive factors for aortic involvement in GCA and for severe aortic injury (dissection, aortic aneurysm) are unknown [33]. Through our study, it seems that outcome is worse in IA than it is in GCA-related aortitis. In this way, proportions of new aortic aneurism and of patients requiring aortic surgery were higher during IA. However, this distinction might be due to differences in inflammatory stage at the time of diagnosis.

Our study provides new informations regarding IA, which is an uncommon disorder characterized by giant cells or lymphoplasmacytic inflammation of the aorta; female gender, smoking, and older age are possible risk factors for the disease [15, 23]. IA appears as a multifocal and progressive aortic disease [23]. In patients with IA starting at the ascending aorta, subsequent distal aortic aneurysms and/or dissections occur in almost $50 \%$ of cases [34]. Studies specifically focusing on the long-term follow-up of ascending IA are very limited.

Herein, we particularly show that GCA-related aortitis and IA over 60y share numerous remarkable similarities in terms of age, inflammatory parameters, sex-ratio, location of aortic involvement and risk of development of new aortic aneurism. By the way, 17/44 IA patients were considered as having GCA by the clinicians. IA in patients over 60y should lead to perform TAB, and if negative, should be considered as authentic GCA with negative TAB. The term "IA" has sometimes been used to design aortitis occurring in patients with prior systemic disease. Among 52 cases of IA reported by Rojo-Leyva et al., 4 had prior 
diagnosis of GCA (positive TAB in 2 cases), up to 8 years before aortitis [15]. The term GCA-related aortitis" would be more suitable in this situation.

On the opposite, IA under $60 \mathrm{y}$ affects males as much as females, and involvement of descending aorta is less frequent. Above all, the prognosis of IA under 60y seems to be worse regarding the development of aortic aneurism. The higher proportion of smokers in this subgroup of patients could explain this point.

Few studies comparing IA and GCA have been conducted so far. As in our study, Talarico et al. found that patients with IA were younger with a different male/female sex-ratio than the one usually noted in GCA [16]. However, aortitis was asserted by aortic abnormal $\left[{ }^{18} \mathrm{~F}\right]$ fluorodeoxyglucose PET uptake, and only $18 \%$ of the patients with GCA underwent aortic PET-scan to look for aortitis. Moreover, patients with "isolated aortitis" under 50y were excluded as they only reviewed medical notes of patients with suspicion of GCA.

Our study has several limits, mainly due to its retrospective design. Monitoring of aortitis was not performed in each patient. Our cohort is homogenous in that aortic CT-scan was the unique imaging technique to diagnose aortitis, but precise modalities of CT-scan may differ between radiologists and centers. Treatment of aortitis was not standardized and data are lacking about the duration, the decrease protocol, and the cumulative dose of steroids. Moreover, data regarding levels of inflammatory parameters during follow up are not provided. We hypothesize that uncontrolled aortitis may lead to aortic complications such aneurism but our data do not allow us to be affirmative. Management of cardiovascular risk factors, which is not precisely described in the follow-up of our patients, also represents an important issue to prevent such complications.

\section{Conclusion}


This work provides new data regarding initial characteristics and outcome of patients with aortitis seen in French internal medicine units. GCA-related aortitis and IA are the main causes of aortitis. IA appears to be more severe at the time of diagnosis, with more frequent aortic aneurisms and higher aortic wall thickenings. The screening for aortitis at the time of diagnosis of GCA enables early diagnosis. From this perspective, we speculate that early diagnosis of aortitis would be a potential mean to better prevent aortic aneurism development, but this remains to be established. Our main finding is that IA in patients $\geq 60 \mathrm{y}$ share many similarities with GCA-related aortitis: mean age around 70y, predominance of women, identical inflammatory parameters, same risk for development of aortic complications. This raises the question of the potential place of aortitis as a criteria for the diagnosis of GCA.

Funding: none

Contributors: all authors meet the criteria for authorship.

\section{Competing interests: none.}

Provenance and peer review: not commissioned; externally peer reviewed. 


\section{References:}

[1] Gornik HL, Creager MA. Aortitis. Circulation 2008; 117: 3039-51.

[2] Stone JR, Bruneval P, Angelini A, et al. Consensus statement on surgical pathology of the aorta from the Society for Cardiovascular Pathology and the Association for European Cardiovascular Pathology: I. Inflammatory diseases. Cardiovasc Pathol 2015; 24: 267-78.

[3] Miller DV, Isotalo PA, Weyand CM, Edwards WD, Aubry M-C, Tazelaar HD. Surgical pathology of noninfectious ascending aortitis: a study of 45 cases with emphasis on an isolated variant. Am J Surg Pathol 2006; 30: 1150-8.

[4] Pipitone N, Salvarani C. Idiopathic aortitis: an underrecognized vasculitis. Arthritis Res Ther 2011; 13: 119.

[5] Hiratzka LF, Bakris GL, Beckman JA, et al. 2010

ACCF/AHA/AATS/ACR/ASA/SCA/SCAI/SIR/STS/SVM Guidelines for the diagnosis and management of patients with thoracic aortic disease. A Report of the American College of Cardiology Foundation/American Heart Association Task Force on Practice Guidelines, American Association for Thoracic Surgery, American College of Radiology,American Stroke Association, Society of Cardiovascular Anesthesiologists, Society for Cardiovascular Angiography and Interventions, Society of Interventional Radiology, Society of Thoracic Surgeons, and Society for Vascular Medicine. J Am Coll Cardiol 2010; 55: e27-129.

[6] Berti A, Campochiaro C, Cavalli G, et al. Giant cell arteritis restricted to the limb arteries: an overlooked clinical entity. Autoimmun Rev 2015; 14: 352-7.

[7] Marie I, Proux A, Duhaut P, et al. Long-term follow-up of aortic involvement in giant cell arteritis: a series of 48 patients. Medicine (Baltimore) 2009; 88: 182-92.

[8] Agard C, Barrier J-H, Dupas B, et al. Aortic involvement in recent-onset giant cell (temporal) arteritis: a case-control prospective study using helical aortic computed tomodensitometric scan. Arthritis Rheum 2008; 59: 670-6.

[9] Prieto-González S, Arguis P, García-Martínez A, et al. Large vessel involvement in biopsy-proven giant cell arteritis: prospective study in 40 newly diagnosed patients using CT angiography. Ann Rheum Dis 2012; 71: 1170-6.

[10] Pipitone N, Versari A, Salvarani C. Role of imaging studies in the diagnosis and follow-up of large-vessel vasculitis: an update. Rheumatol Oxf Engl 2008; 47: 403-8.

[11] Chowdhary VR, Crowson CS, Bhagra AS, Warrington KJ, Vrtiska TJ. CT angiographic imaging characteristics of thoracic idiopathic aortitis. J Cardiovasc Comput Tomogr 2013; 7: 297-302.

[12] Espitia O, Agard C. [Aortitis in giant cell arteritis and its complications]. Rev Med Interne 2013; 34: 412-20. 
[13] Daumas A, Rossi P, Bernard-Guervilly F, et al. [Clinical, laboratory, radiological features, and outcome in 26 patients with aortic involvement amongst a case series of 63 patients with giant cell arteritis]. Rev Med Interne 2014; 35: 4-15.

[14] Espitia O, Néel A, Leux C, et al. Giant Cell Arteritis with or without Aortitis at Diagnosis. A Retrospective Study of 22 Patients with Longterm Followup. $J$ Rheumatol 2012; 39: 2157-62.

[15] Rojo-Leyva F, Ratliff NB, Cosgrove DM 3rd, Hoffman GS. Study of 52 patients with idiopathic aortitis from a cohort of 1,204 surgical cases. Arthritis Rheum 2000; 43: 901-7.

[16] Talarico R, Boiardi L, Pipitone N, et al. Isolated aortitis versus giant cell arteritis: are they really two sides of the same coin? Clin Exp Rheumatol 2014; 32: S55-8.

[17] Hartlage GR, Palios J, Barron BJ, et al. Multimodality imaging of aortitis. JACC Cardiovasc Imaging 2014; 7: 605-19.

[18] Hunder GG, Bloch DA, Michel BA, et al. The American College of Rheumatology 1990 criteria for the classification of giant cell arteritis. Arthritis Rheum 1990; 33: 1122-8.

[19] Arend WP, Michel BA, Bloch DA, et al. The American College of Rheumatology 1990 criteria for the classification of Takayasu arteritis. Arthritis Rheum 1990; 33: 1129-34.

[20] Ishikawa K. Diagnostic approach and proposed criteria for the clinical diagnosis of Takayasu's arteriopathy. J Am Coll Cardiol 1988; 12: 964-72.

[21] Jennette JC, Falk RJ, Bacon PA, et al. 2012 revised International Chapel Hill Consensus Conference Nomenclature of Vasculitides. Arthritis Rheum 2013; 65: 1-11.

[22] Burke AP, Tavora F, Narula N, Tomaszewski JE, Virmani R. Aortitis and ascending aortic aneurysm: description of 52 cases and proposal of a histologic classification. Hum Pathol 2008; 39: 514-26.

[23] Liang KP, Chowdhary VR, Michet CJ, et al. Noninfectious ascending aortitis: a case series of 64 patients. J Rheumatol 2009; 36: 2290-7.

[24] Zenone T, Puget M. Dry cough is a frequent manifestation of giant cell arteritis. Rheumatol Int 2013; 33: 2165-8.

[25] Bienvenu B, Ly KH, Lambert $\mathrm{M}$, et al. [Management of giant cell arteritis: Recommendations of the French Study Group for Large Vassel Vasculitis (GEFA) ]. Rev Med Interne 2016; Jan 28. pii: S0248-8663(15)01130-3. doi: 10.1016/j.revmed.2015.12.015. [Epub ahead of print] PMID: 26833145.

[26] Evans J, Hunder GG. The implications of recognizing large-vessel involvement in elderly patients with giant cell arteritis. Curr Opin Rheumatol 1997; 9: 37-40.

[27] Klein RG, Hunder GG, Stanson AW, Sheps SG. Large artery involvement in giant cell (temporal) arteritis. Ann Intern Med 1975; 83: 806-12. 
[28] Warrington KJ, Matteson EL. Management guidelines and outcome measures in giant cell arteritis (GCA). Clin Exp Rheumatol 2007; 25: 137-41.

[29] Mukhtyar C, Guillevin L, Cid MC, et al. EULAR recommendations for the management of large vessel vasculitis. Ann Rheum Dis 2009; 68: 318-23.

[30] Martinez-Taboada VM, Lopez-Hoyos M, Narvaez J, et al. Effect of antiplatelet/anticoagulant therapy on severe ischemic complications in patients with giant cell arteritis: a cumulative meta-analysis. Autoimmun Rev 2014; 13: 788-94.

[31] Kermani TA, Warrington KJ, Crowson CS, et al. Large-vessel involvement in giant cell arteritis: a population-based cohort study of the incidence-trends and prognosis. Ann Rheum Dis 2013; 72: 1989-94.

[32] Agard C, Ponge T, Fradet G, et al. Giant cell arteritis presenting with aortic dissection: two cases and review of the literature. Scand J Rheumatol 2006; 35: 233-6.

[33] Bongartz T, Matteson EL. Large-vessel involvement in giant cell arteritis. Curr Opin Rheumatol 2006; 18: 10-7.

[34] Wang H, Smith RN, Spooner AE, et al. Giant cell aortitis of the ascending aorta without signs or symptoms of systemic vasculitis is associated with elevated risk of distal aortic events. Arthritis Rheum 2012; 64: 317-9. 
Figure 1: flow chart of patient's selection.

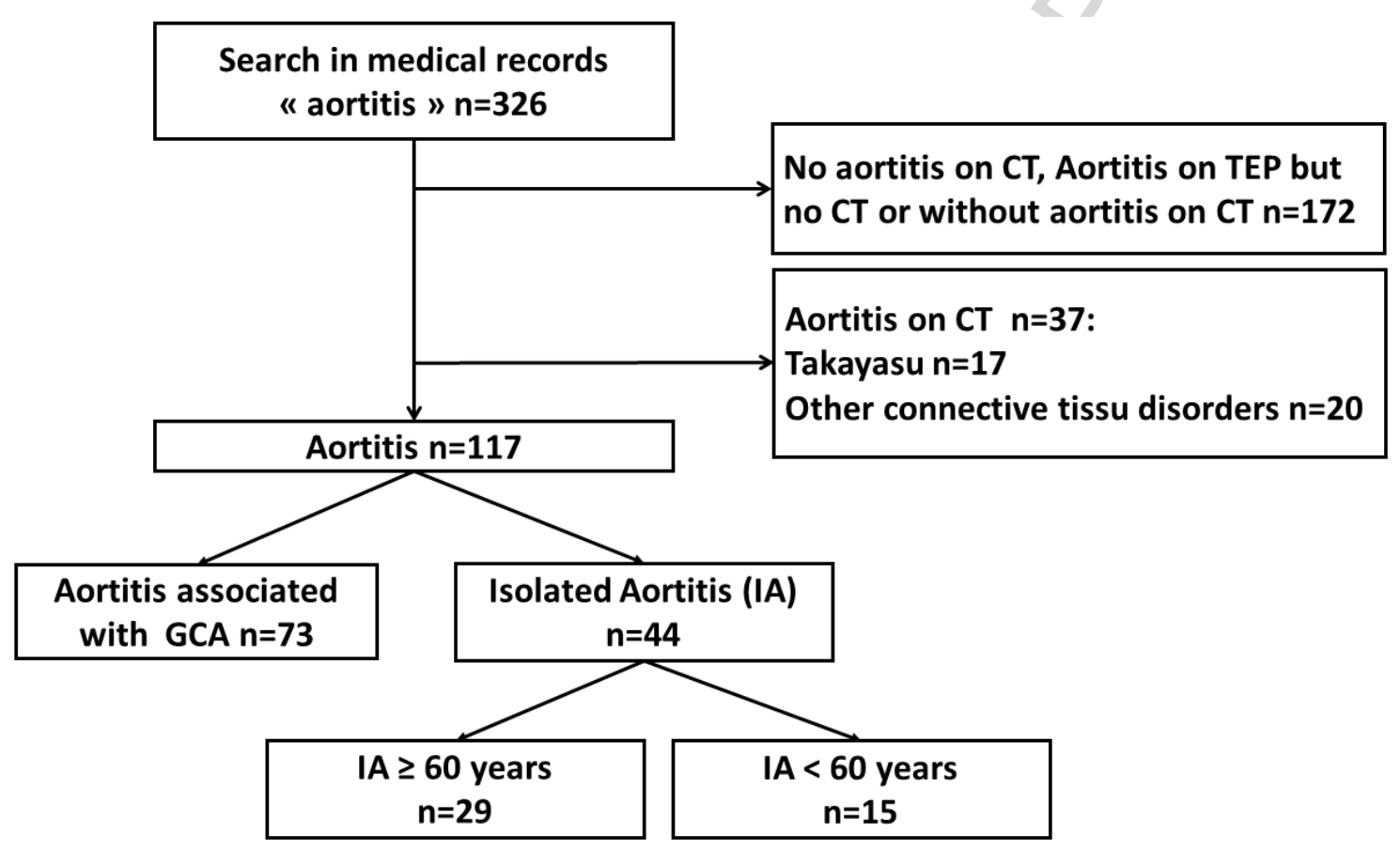


Figure 2: Long-term survival comparison of patients with GCA-related aortitis (GCA) and idiopathic aortitis (IA). In each type of aortic event (aortic aneurism, aortic surgery, aortic dissection), only subsequent aortic events are taken into account in patients free of the event at diagnosis. Figure 2A shows free of aortic aneurism survival, figure $2 \mathrm{~B}$ shows free of aortic surgery survival, figure $2 \mathrm{C}$ shows free of aortic dissection survival. Free of aortic aneurysm survival in patients with GCA-related aortitis, IA $\geq 60 \mathrm{y}$ and $\mathrm{IA}<60 \mathrm{y}$ is shown on figure 2D.

A

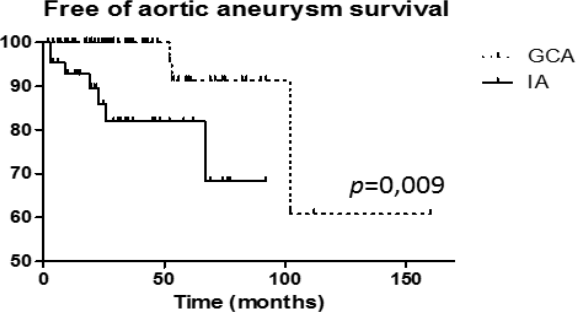

C

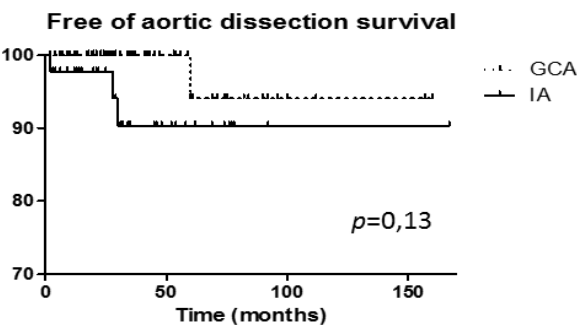

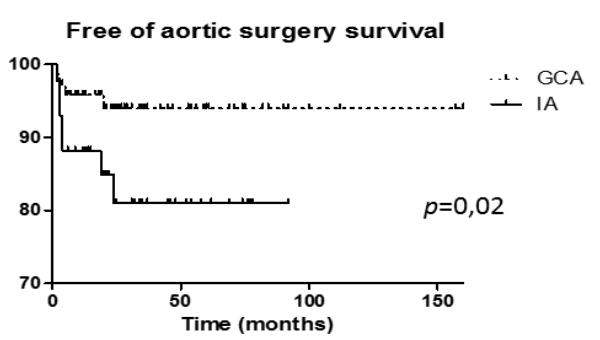

B

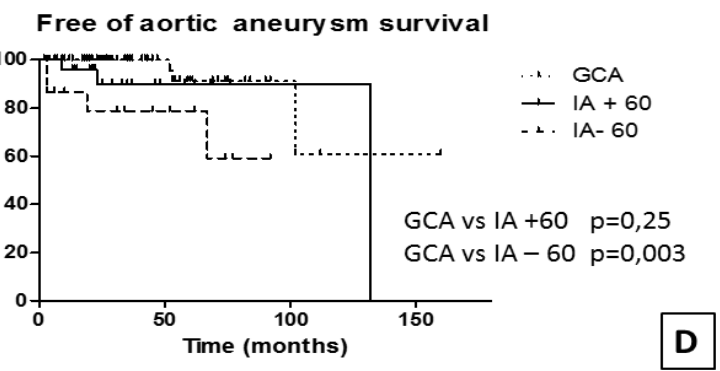




\section{Highlights}

- At the time of diagnosis of aortitis, aortic aneurisms are more frequent and aortic wall is more thickened in patients with IA than in patients with GCA-related aortitis.

- IA represents a heterogenous group of patients, with numerous smokers, especially in patients under $60 \mathrm{y}$.

- IA in patients $\geq 60 \mathrm{y}$ share many similarities with GCA-related aortitis: mean age around $70 \mathrm{y}$, predominance of women, identical inflammatory parameters, same risk for development of aortic complications. 